\title{
Characteristic Analysis of Photovoltaic On-Grid System In Tropical Region For Weather-Corrected Performance Ratio Calculation Method Implementation
}

\author{
Erfan Syahputra ${ }^{1}$, Rio Agustian Fajarin ${ }^{1}$, Eko Adhi Setiawan ${ }^{* 1,2}$ \\ ${ }^{1}$ Department of Electrical Engineering, Faculty of Engineering, Universitas Indonesia, \\ Kampus Baru UI Depok, Depok 16424, Indonesia \\ ${ }^{2}$ Tropical Renewable Energy Center (TREC), Faculty of Engineering, Universitas Indonesia, \\ Kampus Baru UI Depok, Depok 16424, Indonesia
}

\begin{abstract}
Indonesia has different weather factors than the subtropical climate that influences the performance indicators of photovoltaic systems. One of them is performance ratio that is affected by temperature factors. NREL proposes calculation method of Weather-Corrected Performance Ratio for correcting factors (temperature) in calculation performance ratio of photovoltaic systems. However, the implementation of this method in real operating condition of photovoltaic system especially in the tropics, has not received special attention. In addition, temperature coefficient of power photovoltaic $(\delta)$ in Standard Test Condition, is used in the calculation method may be different in real operating condition. This study was conducted to determine the effects of weather-corrected performance ratio method and to know characteristic of temperature coefficient of power photovoltaic $(\delta)$ as factors in of weather-corrected performance ratio method, in real operating condition especially in tropics. Through analysis photovoltaic system data from the data logger it is found that the range values of weather-corrected performance ratio are greater than conventional methods, with a maximum increase of $2.43 \%$. Moreover it is found that because average temperature of tropical climate is higher than subtropical climate, it makes the percentage of power decrease to rise in temperature $(\delta)$ in tropical climate is higher than subtropical climate.
\end{abstract}

Keywords: photovoltaic system, performance ratio, weather-corrected performance ratio, temperature coefficient of power photovoltaic $(\delta)$

\section{Introduction}

Indonesia is located in the tropics so it has greater solar energy potential than other countries with different climate. Nevertheless, the development of photovoltaic systems as power plants in Indonesia is still lacking. Especially since it is in tropical climate, Indonesia has different climatic and weather conditions from other photovoltaic systems in other climates that may affect the process of evaluating the performance of the photovoltaic system used.

One of the influenced indicators is performance ratio. According to IEC 61724 standards, performance ratio is defined as the ratio between the duration of energy consumption by the load when the maximum power of the photovoltaic system with the effective duration of solar radiation in a day (peak sun hour). On a system connected to the utility network (on-grid), the energy generated by the system is directly supplied to the network (the utility network is considered a load). Thus, on an on-grid photovoltaic system, performance ratio is defined as the actual energy ratio generated by the system with known nominal energy (theoretical) of the system power rating.

However, the performance ratio is also influenced by weather factors, especially the temperature factor. The Weather-Corrected Performance Ratio method is proposed by the National Renewable Energy Laboratory (NREL) to correct the weather factor (temperature) of the photovoltaic system in calculating the performance ratio thereby reduce the weather variation from the conventional performance ratio results according to IEC 61724 based on simulation that they did [10]. However, the implementation of the use of this method under the operating conditions of photovoltaic systems in an environment that has not received special attention, especially in the tropics. In addition, in the calculation method, modification coefficient of module power to temperature $(\delta)$ in standard test state (STC) may be different if in actual condition.

Therefore, this study was conducted to determine the effect of weather-corrected performance ratio method in actual tropical environment conditions on on-grid photovoltaic system and to know the coefficient value of change of module power to temperature $(\delta)$ as correction factor in weather-corrected method performance ratio on the actual conditions in the tropics.

\section{Performance Ratio Review}

Performance Ratio (PR) is an indicator used to measure performance of photovoltaic system. The higher the PR of the system, the better is the performance of the system as compared to other systems in similar climatic

Corresponding author: ekoas@eng.ui.ac.id 
conditions [1]. In this paper we explain two methodologies that used to calculate performance ratio

\subsection{IEC 61724 Methodology}

According to IEC 61724 Standard, performance ratio is ratio between final yield and reference yield of photovoltaic system [2].

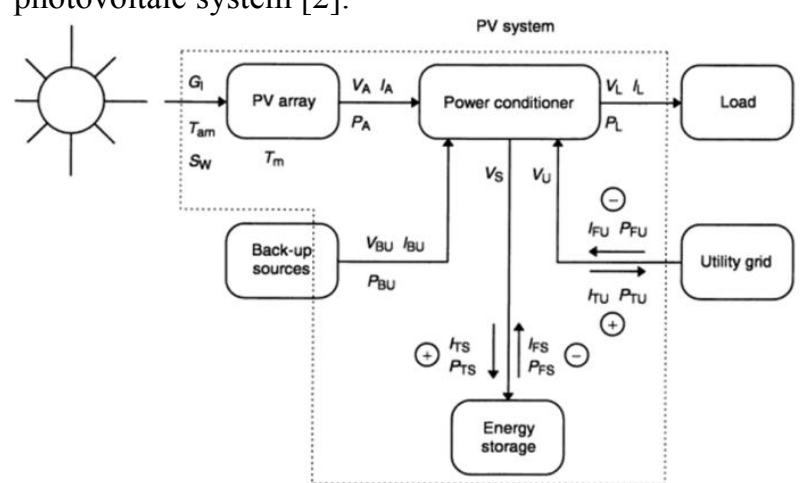

Figure 1 Parameters to be measured in real time (adopted from IEC 61724)

Here are equations that used to calculate performance ratio:

$$
\begin{aligned}
& Y_{f}=Y_{A} \cdot \eta_{\mathrm{LOAD}} \\
& Y_{A}=\frac{E_{A, d}}{P_{0}}=\tau \times \frac{\left(\Sigma_{\text {day }} P_{A}\right)}{P_{0}} \\
& \eta_{\mathrm{LOAD}}=\frac{E_{U S E, \tau}}{E_{\text {in, } \tau}} \\
& Y_{r}=\tau_{\mathrm{r}} \times \frac{\left(\Sigma_{\text {day }} \mathrm{G}_{\mathrm{I}}\right)}{\mathrm{G}_{\mathrm{I}, \mathrm{ref}}}
\end{aligned}
$$$$
\text { Performance Ratio }(\boldsymbol{R p})=\boldsymbol{Y}_{\boldsymbol{f}} / \boldsymbol{Y}_{\boldsymbol{r}}(1)
$$

Where:

- $\quad \boldsymbol{R}_{\boldsymbol{p}}$ : performance ratio

- $\boldsymbol{Y}_{\boldsymbol{f}}$ : final yield

- $\boldsymbol{Y}_{\boldsymbol{r}}$ : reference yield

- $\boldsymbol{Y}_{\boldsymbol{A}}$ : array yield

- $\boldsymbol{E}_{\boldsymbol{A}, \boldsymbol{d}}$ : the daily array total output energy

- $\boldsymbol{P}_{\mathbf{0}}$ : rated output power, $\mathrm{kW}$ of installed PV array

- $\boldsymbol{\eta}_{\text {LOAD }}$ : load efficiency

- $\quad \mathbf{E}_{\mathbf{U S E}, \tau}$ : total system output energy

- $\mathbf{E}_{\mathbf{i n}, \tau}$ : total system input energy

- $\boldsymbol{\tau}_{\mathbf{r}} \times\left(\sum_{\text {day }} \mathbf{G}_{\mathbf{I}}\right)$ : total daily in-plane irradiation

- $\mathbf{G}_{\mathbf{I}, \text { ref }}$ : module's reference in-plane irradiance, $\mathbf{G}_{\mathbf{I}, \mathbf{r e f}}=1000 \mathrm{~W} / \mathrm{m}^{2}$

These equations, applied in both on-grid and off-grid system. However, in on-grid system, the load efficiency can be ignored because the system directly connected to utility grid. So we can view performance ratio as ratio of the actual AC energy delivered from the system to nominal (theoretical) energy from rated output power [3].

\subsection{Weather-Corrected Performance Ratio}

Although performance ratio is an indicator that globally accepted, it values is susceptible to weather factors especially temperature that affect its value and cause variations in its value. NREL consider this factor and proposes a method to reduce this effect. This calculation method is weather-corrected performance ratio [4].

The following is the result of the method from simulation.

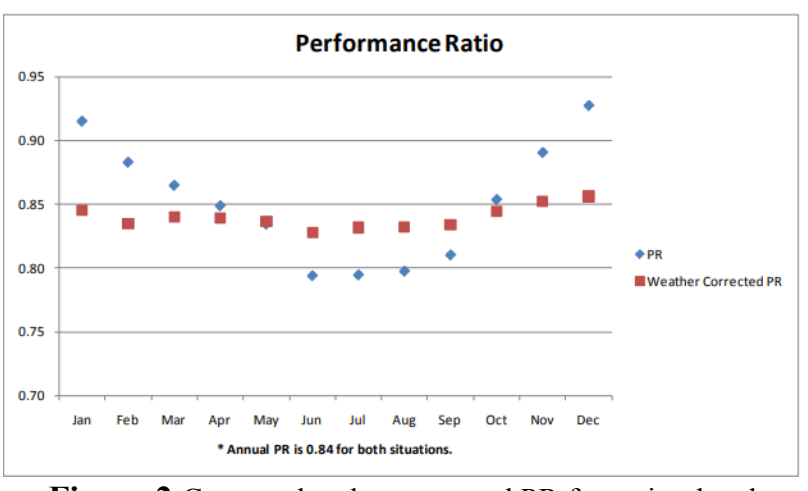

Figure 2 Corrected and uncorrected PR from simulated results

Here is the equation:

$$
P \boldsymbol{R}_{\text {corr }}=\frac{\Sigma_{i} E N_{A C, i}}{\Sigma_{i}\left[P_{S T C}\left(\frac{G_{P O A, i}}{G_{S T C}}\right)\left(1-\frac{\delta}{100}\left(T_{\text {cell, }, \text { typ, }, \text { avg }}-T_{\text {cell }, i}\right)\right)\right]}
$$

Where:

- $\quad \mathbf{P R}_{\text {corr }}$ : weather-corrected performance ratio

- $\quad \mathbf{E N}_{\mathbf{A C}}$ : the measured AC electrical generation $(\mathrm{kW})$

- $\quad \mathbf{P}_{\text {STC }}$ : the summation of installed modules' power rating from flash test data $(\mathrm{kW})$

- $\mathbf{G}_{\mathbf{P O A}}$ : the measured plane of array (POA) irradiance $\left(\mathrm{kW} / \mathrm{m}^{2}\right)$

- $\mathbf{G}_{\mathrm{STC}}$ : irradiance at STC, $\mathrm{G}_{\mathrm{STC}}=1 \mathrm{~kW} / \mathrm{m}^{2}$

- $\mathbf{T}_{\text {cell_typ_avg }}$ : average cell temperature computed from one year of weather data using the project weather file $\left({ }^{\circ} \mathrm{C}\right)$

- $\quad \mathbf{T}_{\text {cell_ }}$ : cell temperature computed from measured meteorological data $\left({ }^{\circ} \mathrm{C}\right)$

- $\quad \boldsymbol{\delta}$ : temperature coefficient for power $\left(\% /{ }^{\circ} \mathrm{C}\right)$ at STC

However, in real operating condition the value of temperature coefficient for power $(\delta)$ varies in different level of irradiance of array [4].

\section{Methodology}

First we need to know the results from both calculation methods, performance ratio by IEC 61724 standard and corrected performance ratio by NREL. 
Here is the on-grid photovoltaic system in tropics that used to this research.

Table 1. List Of Photovoltaic On-Grid System In Tropics That Used In This Research

\begin{tabular}{|c|c|c|c|c|c|c|c|}
\hline \multirow{2}{*}{ No. } & \multirow{2}{*}{ Name Code } & \multirow{2}{*}{ Country } & \multicolumn{2}{|c|}{ Coordinate (Decimal) } & \multirow{2}{*}{ Technology } & \multirow{2}{*}{$\begin{array}{c}\text { Rated Power } \\
\text { Output }\end{array}$} & \multirow{2}{*}{ Data Log Duration } \\
\hline & & & Latitude & Longitude & & & \\
\hline 1. & Poly-Depok & Indonesia & $-6,362203$ & 106,823488 & Polycrys talline & $1,200 \mathrm{kWp}$ & 1 August 2015 - 31 August 2016 \\
\hline 2. & Mono-Shah & Malaysia & 3,068734 & 101,496948 & Monocrystalline & $9,000 \mathrm{kWp}$ & 1 July 2017 - 31 July 2017 \\
\hline 3. & \begin{tabular}{|l|} 
Poly-Shah \\
\end{tabular} & Malaysia & 3,068734 & 101,496945 & Polycrystalline & $5,405 \mathrm{kWp}$ & 1 July 2017 - 31 July 2017 \\
\hline 4. & Thin-Shah & Malaysia & 3,068734 & 101,496945 & $\begin{array}{l}\text { Amorphous } \\
\text { Silicon (Thin- } \\
\text { Film) }\end{array}$ & $0,900 \mathrm{kWp}$ & 2 June 2017 - 21 June 2017 \\
\hline
\end{tabular}

Poly-Depok system data was obtained directly from its data logger in Depok, Indonesia. Other systems were obtained from their respective data logger that store in database website of PV in APEC region. These systems are from Shah Alam, Selangor, Malaysia.

To measure variation in both performance ratio and corrected performance ratio we use standard deviation and range from these methods. In addition to measure performance ratio, all of these systems used to measure temperature coefficient for power $\left(\% /{ }^{\circ} \mathrm{C}\right)$ at real operating condition, especially in tropics. These results would be compared from real operating condition in subtropics. Data from subtropics were obtained from a journal titled "Study of the Temperature Coefficients of Amorphous and Polycrystalline Silicon Photovoltaic Modules under Real Operating Conditions", by Plamen Tsankov. This journal uses photovoltaic system data from Technical University of Gabrovo (TUG), Bulgaria [5]. It record the data for one year.

\section{Results And Discussion}

\subsection{Comparison of Performance Ratio \& Weather-Corrected Performance Ratio}

Here are the monthly performance ratio and corrected performance ratio of Poly-Depok system:
Table 2. Monthly Performance Ratio And Corrected Performance Ratio Of Poly-Depok

\begin{tabular}{|c|c|c|}
\hline Month & PR (\%) & PR corr (\%) \\
\hline Aug-15 & 67.23 & 67.19 \\
\hline Sep-15 & 72.84 & 73.06 \\
\hline Oct-15 & 57.21 & 57.74 \\
\hline Nov-15 & 79.56 & 80.21 \\
\hline Dec-15 & 73.04 & 73.19 \\
\hline Jan-16 & N/A & N/A \\
\hline Feb-16 & N/A & N/A \\
\hline Mar-16 & 70.05 & 70.05 \\
\hline Apr-16 & 72.66 & 72.51 \\
\hline May-16 & 71.58 & 71.37 \\
\hline Jun-16 & 70.45 & 70.02 \\
\hline Jul-16 & 68.43 & 67.95 \\
\hline Aug-16 & 71.43 & 71.27 \\
\hline Standard Deviation & 5.16 & 5.17 \\
\hline Maximum & 79.56 & 80.21 \\
\hline Minimum & 57.21 & 57.74 \\
\hline Range & 22.35 & 22.47 \\
\hline
\end{tabular}

Aside from data error in January and February, the value of standard deviation and range of corrected performance ratio is slightly higher than performance ratio. Here are the daily performance ratio and corrected performance ratio of Mono-Shah system: 
Table 3. Daily Performance Ratio And Corrected Performance Ratio Of Mono-Shah

\begin{tabular}{|c|c|c|}
\hline Date & PR (\%) & PR corr $(\%)$ \\
\hline $7 / 1 / 2017$ & 59.17 & 58.68 \\
\hline $7 / 2 / 2017$ & 56.8 & 57.85 \\
\hline $7 / 3 / 2017$ & 60.54 & 60.74 \\
\hline $7 / 4 / 2017$ & 62.74 & 61.58 \\
\hline $7 / 5 / 2017$ & 57.13 & 57.94 \\
\hline $7 / 6 / 2017$ & 63.88 & 62.78 \\
\hline $7 / 7 / 2017$ & 59.59 & 58.8 \\
\hline $7 / 8 / 2017$ & 45.06 & 45.98 \\
\hline $7 / 9 / 2017$ & 44.86 & 42.87 \\
\hline $7 / 10 / 2017$ & 47.14 & 44.61 \\
\hline $7 / 11 / 2017$ & 59.4 & 59.07 \\
\hline $7 / 12 / 2017$ & 63.18 & 62.58 \\
\hline $7 / 13 / 2017$ & 58.71 & 58.2 \\
\hline $7 / 14 / 2017$ & 58.63 & 59.37 \\
\hline $7 / 15 / 2017$ & 62.31 & 61.77 \\
\hline $7 / 16 / 2017$ & 58.15 & 59 \\
\hline $7 / 17 / 2017$ & 59.23 & 59.61 \\
\hline $7 / 18 / 2017$ & 60.32 & 59.93 \\
\hline $7 / 19 / 2017$ & 62.34 & 61.55 \\
\hline $7 / 20 / 2017$ & 60.9 & 60.54 \\
\hline $7 / 21 / 2017$ & 60.62 & 61.29 \\
\hline $7 / 22 / 2017$ & 58.81 & 59.14 \\
\hline $7 / 23 / 2017$ & 54.02 & 55.73 \\
\hline $7 / 24 / 2017$ & 59.59 & 58.56 \\
\hline $7 / 25 / 2017$ & 59.98 & 59.35 \\
\hline $7 / 26 / 2017$ & 55.34 & 56.46 \\
\hline $7 / 27 / 2017$ & 56.56 & 56.92 \\
\hline $7 / 28 / 2017$ & 59.34 & 59.68 \\
\hline $7 / 29 / 2017$ & 59.4 & 59.57 \\
\hline $7 / 30 / 2017$ & 58.71 & 58.12 \\
\hline $7 / 31 / 2017$ & 55.73 & 56.09 \\
\hline Standard Deviation & 4.61 & 4.73 \\
\hline Maximum & 63.88 & 62.78 \\
\hline Minimum & 44.86 & 42.87 \\
\hline Range & 19.02 & 19.91 \\
\hline
\end{tabular}

Same with Poly-Depok, standard deviation and range of corrected performance ratio is slightly higher than performance ratio. The following are the daily performance ratio and corrected performance ratio of Poly-Shah system:
Table 4. Daily Performance Ratio And Corrected Performance Ratio Of Poly-Shah

\begin{tabular}{|c|c|c|}
\hline Date & PR (\%) & PR corr $(\%)$ \\
\hline $7 / 1 / 2017$ & 75.57 & 75.13 \\
\hline $7 / 2 / 2017$ & 73.28 & 74.93 \\
\hline $7 / 3 / 2017$ & 75.67 & 75.65 \\
\hline $7 / 4 / 2017$ & 76.47 & 77.5 \\
\hline $7 / 5 / 2017$ & 73.9 & 75.43 \\
\hline $7 / 6 / 2017$ & 78.7 & 77.69 \\
\hline $7 / 7 / 2017$ & 77.79 & 76.37 \\
\hline $7 / 8 / 2017$ & 75.03 & 71.35 \\
\hline $7 / 9 / 2017$ & 74.69 & 70.8 \\
\hline $7 / 10 / 2017$ & 78.5 & 73.63 \\
\hline $7 / 11 / 2017$ & 74.47 & 73.6 \\
\hline $7 / 12 / 2017$ & 78 & 77.13 \\
\hline $7 / 13 / 2017$ & 73.59 & 73.33 \\
\hline $7 / 14 / 2017$ & 73.82 & 75.03 \\
\hline $7 / 15 / 2017$ & 75.9 & 74.91 \\
\hline $7 / 16 / 2017$ & 74.72 & 76.19 \\
\hline $7 / 17 / 2017$ & 73.13 & 74.35 \\
\hline $7 / 18 / 2017$ & 77.3 & 77.46 \\
\hline $7 / 19 / 2017$ & 78 & 77.29 \\
\hline $7 / 20 / 2017$ & 75.69 & 75.52 \\
\hline $7 / 21 / 2017$ & 79.17 & 79.73 \\
\hline $7 / 22 / 2017$ & 75.84 & 75.89 \\
\hline $7 / 23 / 2017$ & 72.8 & 74.86 \\
\hline $7 / 24 / 2017$ & 77.1 & 78.34 \\
\hline $7 / 25 / 2017$ & 78.55 & 77.26 \\
\hline $7 / 26 / 2017$ & 72.67 & 74.32 \\
\hline $7 / 27 / 2017$ & 72.99 & 73.78 \\
\hline $7 / 28 / 2017$ & 74.87 & 75.58 \\
\hline $7 / 29 / 2017$ & 74.7 & 75.28 \\
\hline $7 / 30 / 2017$ & 75.65 & 74.84 \\
\hline $7 / 31 / 2017$ & 72.76 & 73.89 \\
\hline Standard Deviation & 1.96 & 1.88 \\
\hline Maximum & 79.17 & 79.73 \\
\hline Minimum & 72.67 & 70.8 \\
\hline Range & 6.5 & 8.93 \\
\hline
\end{tabular}

Different from others, here the standard deviation is slightly lower. However, the range is still higher, and more significant than standard deviation. And the lasts are the daily performance ratio and corrected performance ratio of Thin-Shah system: 
Table 5. Performance Ratio And Corrected Performance Ratio Of Thin-Shah

\begin{tabular}{|c|c|c|}
\hline Date & PR (\%) & PR corr (\%) \\
\hline $6 / 2 / 2017$ & 70.71 & 70.24 \\
\hline $6 / 3 / 2017$ & 73.45 & 74.26 \\
\hline $6 / 4 / 2017$ & 70.38 & 69.08 \\
\hline $6 / 5 / 2017$ & 73.22 & 73.72 \\
\hline $6 / 6 / 2017$ & 71.95 & 72.73 \\
\hline $6 / 7 / 2017$ & 68.56 & 67.33 \\
\hline $6 / 8 / 2017$ & 69.43 & 68.84 \\
\hline $6 / 9 / 2017$ & 73.44 & 73.95 \\
\hline $6 / 10 / 2017$ & 68.15 & 66.99 \\
\hline $6 / 11 / 2017$ & 73.43 & 74.05 \\
\hline $6 / 12 / 2017$ & 72.03 & 71.89 \\
\hline $6 / 13 / 2017$ & 70.77 & 70.75 \\
\hline $6 / 15 / 2017$ & 71.27 & 71.42 \\
\hline $6 / 16 / 2017$ & 71.16 & 71.32 \\
\hline $6 / 17 / 2017$ & 71.56 & 71.79 \\
\hline $6 / 18 / 2017$ & 68.79 & 68.03 \\
\hline $6 / 19 / 2017$ & 71.71 & 71.26 \\
\hline $6 / 20 / 2017$ & 72.17 & 72.89 \\
\hline $6 / 21 / 2017$ & 72.91 & 71.55 \\
\hline Standard Deviation & 1.57 & 71.61 \\
\hline Maximum & 73.45 & 2.14 \\
\hline Minimum & 68.15 & 66.26 \\
\hline Range & 5.3 & 7.27 \\
\hline & & \\
\hline
\end{tabular}

On Thin-Shah, standard deviation and range of corrected performance ratio is slightly higher than performance ratio.

\subsection{Temperature Coefficient Of Power ( $\delta)$ In Real Operating Condition}

On the other hand, these are temperature coefficient for power $(\delta)$ in real operating condition of tropics:

\begin{tabular}{|c|c|c|c|c|c|c|}
\hline \multirow{2}{*}{$\begin{array}{c}\text { Irradiance } \\
\text { Plane Of } \\
\text { Array }\end{array}$} & \multicolumn{7}{|c|}{ Temperature Coefficient For Power $(\delta)\left[\% /{ }^{\circ} \mathrm{C}\right]$} \\
\cline { 2 - 7 } & Poly-Depok & Mono-Shah & Poly-Shah & Thin-Shah & Poly-TUG & Thin-TUG \\
\hline STC & -0.43 & -0.42 & -0.45 & -0.23 & -0.47 & -0.2 \\
\hline $1000 \pm 50$ & -1.18 & 0.19 & -0.07 & -0.31 & -0.48 & -0.52 \\
\hline $900 \pm 50$ & -1.38 & 0.11 & 0.11 & -0.07 & -0.31 & 0.58 \\
\hline $800 \pm 50$ & -1.24 & 0.11 & -0.08 & -0.07 & -0.21 & 1.27 \\
\hline $700 \pm 50$ & -0.66 & 0.01 & -0.07 & -0.03 & -0.18 & 1.48 \\
\hline $600 \pm 50$ & -0.14 & -0.08 & -0.19 & -0.04 & -0.14 & 1.76 \\
\hline $500 \pm 50$ & 0.01 & 0.1 & -0.08 & 0.02 & -0.1 & 1.85 \\
\hline $400 \pm 50$ & 0.05 & 0.25 & 0.03 & 0.04 & -0.08 & 1.49 \\
\hline $300 \pm 50$ & -0.06 & 0.34 & 0.21 & 0.05 & -0.04 & 1.33 \\
\hline $200 \pm 50$ & 0.1 & 0.45 & 0.16 & 0.11 & 0.01 & 1.13 \\
\hline $100 \pm 50$ & 0.15 & 0.26 & 0.11 & 0.13 & 0.07 & 1.06 \\
\hline
\end{tabular}

Furthermore, the following is comparison of temperature coefficient for power $(\delta)$ for polycrystalline in different climate:

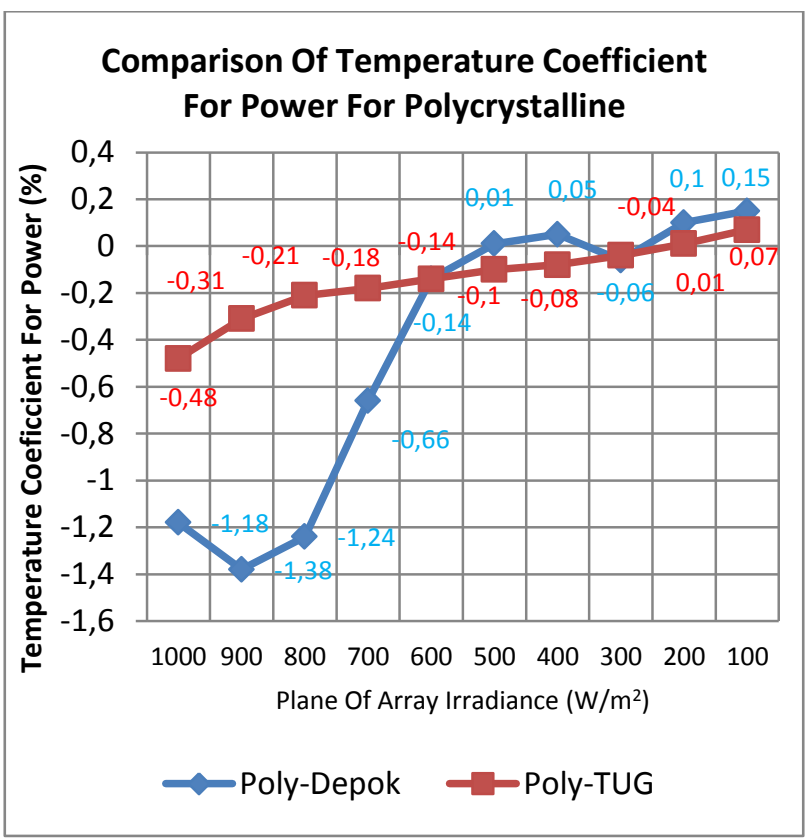

Figure 3 Comparison Of Temperature Coefficient For Power $(\delta)$ For Polycrystalline In Tropics And Subtropics Climate

This is chart of temperature coefficient of power module from Poly-Depok in tropics and Poly-TUG (Technical University of Gabrovo), Bulgaria in subtropics [4]. Both systems are polycrystalline. From the chart above, its visible that at irradiance $700 \mathrm{~W} / \mathrm{m}^{2}$ to $1000 \mathrm{~W} / \mathrm{m}^{2}$, the percentage of power decrease to rise in temperature $(\delta)$ of polycrystalline module in tropics is significantly higher (2,4-5,9 times higher) than subtropics. While at irradiance $100 \mathrm{~W} / \mathrm{m}^{2}$ to $600 \mathrm{~W} / \mathrm{m}^{2}$, we can see that the percentage of power change to rise in temperature approach the same value with some anomaly at irradiance $400 \mathrm{~W} / \mathrm{m}^{2}$ and $500 \mathrm{~W} / \mathrm{m}^{2}$.

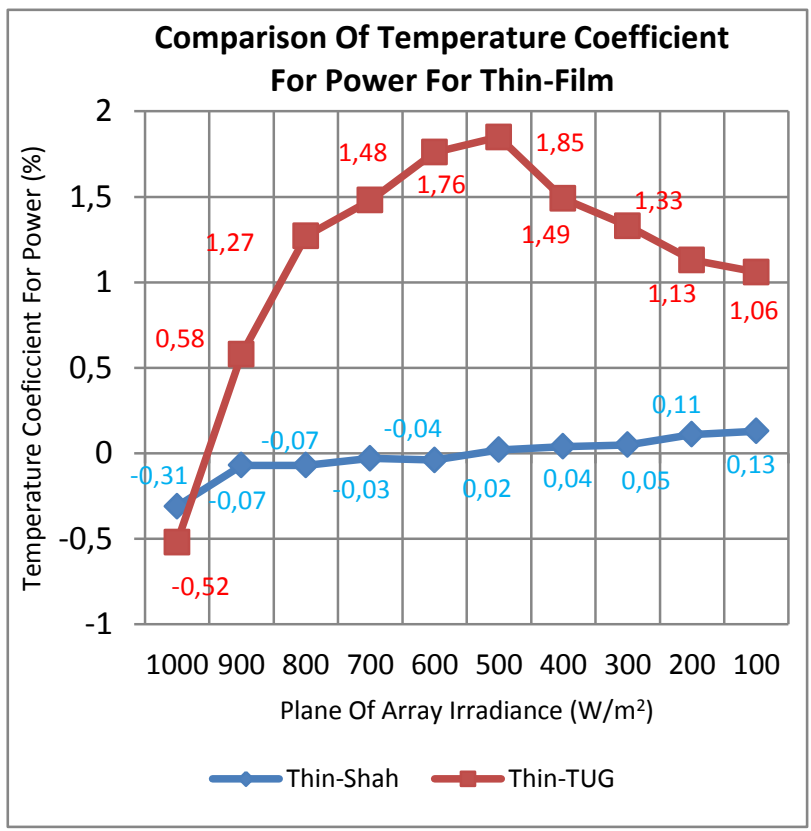

Figure 4 Comparison Of Temperature Coefficient For Power (ס) For Thin-Film In Tropics And Subtropics Climate 
Figure above is chart temperature coefficient of power module of thin-film from Thin-Shah in tropics and Thin-TUG in subtropics. From the chart we found that at irradiance $1000 \mathrm{~W} / \mathrm{m}^{2}$, the percentage of power decrease to rise in temperature in both systems are higher and significant than other irradiances, with subtropics has higher percentage of power decrease to rise in temperature than tropics. While at other irradiances, the percentage of power change to rise in temperature are likely to increase, with the percentage of power increase to rise in temperature are more significant in subtropics than tropics.

\subsection{Climate Impact On Temperature Coefficient Of Power (ס)}

Based on National Aeronautics and Space Administration (NASA) meteorology data, tropical climates have higher mean temperatures than subtropical climates [6]. This affects the temperature coefficient of power $(\delta)$ at different irradiance levels.

According to Sandia National Laboratories, temperature coefficient of power $(\delta)$ can be modelled as a function of irradiance and temperatures for silicon crystalline and silicon amorphous modules [7]. This function is obtained from the calculation using the temperature coefficient of the current $(\alpha)$ and voltage $(\beta)$ modules obtained from the test results according to ASTM (American Standard Testing and Material) standard conditions.

Here is temperature coefficient for power $(\delta)$ of polycrystalline / semi-crystalline as a function of irradiance and temperature:

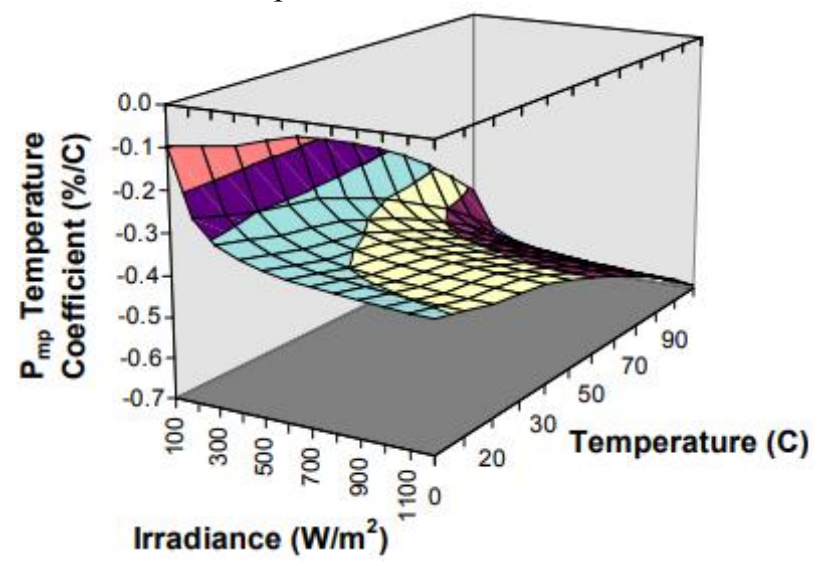

Figure 5 Temperature Coefficient For Power $(\delta)$ Of SemiCrystalline/Polycrystalline (ASE Americas ASE-300-DG/50) As A Function Of Irradiance And Temperature

This graph shows that at constant temperature, the lower irradiance level, the temperature coefficient of module power $(\delta)$ is more positive. This corresponds to the value of the temperature coefficient of power $(\delta)$ under real operating conditions in the tropical climate (Poly-UI) and subtropical (Poly-TUG) climate previously analysed in Figure 3.

Also at constant irradiance level, the higher the temperature, the temperature coefficient of power $(\delta)$ becomes more negative. This also corresponds to the average temperature of modules at Poly-UI system ( 35 ${ }^{\circ} \mathrm{C}$ ) in tropical climate which is higher than the average temperature of module at Poly-TUG system $\left(25.6^{\circ} \mathrm{C}\right)$ in sub-tropical climate. So from Figure 3, we can see that the percentage of power decrease to temperature rise in tropical climate is higher than subtropical climate, especially at high irradiance level $\left(700 \mathrm{~W} / \mathrm{m}^{2}\right.$ to $1000 \mathrm{~W}$ $/ \mathrm{m}^{2}$ ).

While, here is temperature coefficient for power ( $\delta$ ) of amorphous silicon / thin-film as a function of irradiance and temperature:

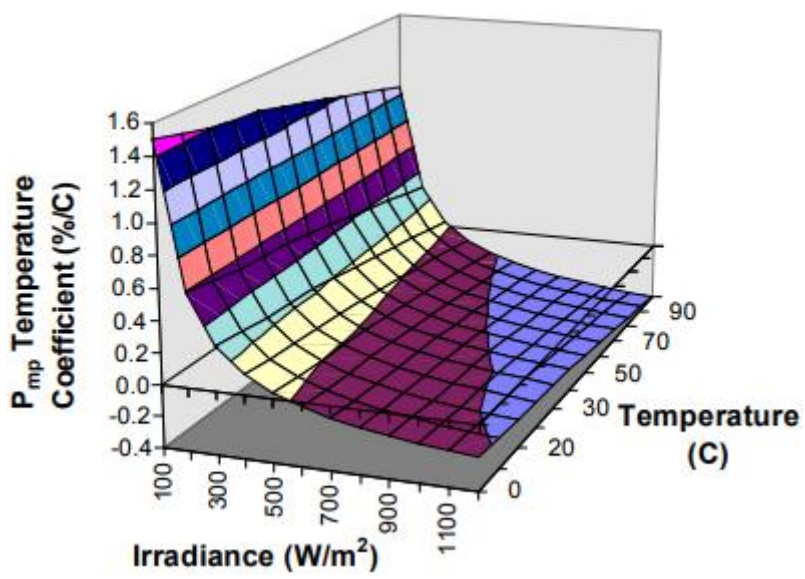

Figure 6 Temperature Coefficient For Power $(\delta)$ Of ThinFilm (USSC UPM-880) As A Function Of Irradiance And Temperature

From the Figure 6, we know that the trend of the temperature coefficient of power $(\delta)$ at constant temperature is also the same as Figure 4. Temperature coefficient of power $(\delta)$ will increase with decreasing irradiance level on panel. While at a constant irradiance level, the temperature coefficient of power $(\delta)$ will be more negative as the module temperature rise. This characteristic corresponds to Figure 4 that the temperature coefficients of power $(\delta)$ on Thin-UiTM system are generally more negative than Thin-TUG system. This is due to the average temperature module of Thin-UiTM system $\left(40.2^{\circ} \mathrm{C}\right)$ is larger than the ThinTUG system $\left(28.9^{\circ} \mathrm{C}\right)$.

However, under real operating conditions there are other factors that may affect the temperature coefficient values of module power such as (humidity, rainfall and dust) so that in Figures 3 and 4, there are few anomalies. However, these factors are less significant overall.

\section{Conclusions}

This paper discuss that corrected performance ratio depends to temperature coefficient for power $(\delta)$ in photovoltaic system at STC. However, in real operating condition this coefficient varies at different level of irradiances. From the several photovoltaic systems in tropics and photovoltaic system data in subtropics in journal titled "Study of the Temperature Coefficients of Amorphous and Polycrystalline Silicon Photovoltaic Modules under Real Operating Conditions", by Plamen Tsankov, we compare temperature coefficient for power 
( $\delta)$ of photovoltaic systems in tropics and subtropics. The results show that, on polycrystalline and amorphous silicon / thin-film photovoltaic systems with constant irradiance levels, the percentage of power decrease in rise to temperature in the tropics is higher than subtropical. This is because the average temperature of tropical climate is higher than subtropical.

\section{Acknowledgements}

The authors would like to thank this work was supported and funded by "Hibah Publikasi Internasional Terindeks Untuk Tugas Akhir Mahasiswa UI (PITTA) Number 2425/UN2.R3.1HKP.05.00/2018".

\section{References}

1. A. M. Khalid, I. Mitra, W. Warmuth, and V. Schacht "Performance ratio - Crucial parameter for grid connected PV plants," Renewable Sustainable Energy Rev., vol. 65, pp. 1139-1158, Nov. 2016.

2. British Standard, "Photovoltaic system performance monitoring — Guidelines for measurement, data exchange and analysis. IEC Standard 61724,” 1998

3. Performance Ratio-Quality Factor for the PV plantsSMA, Web. 22 May 2018. Accessed from: 〈http://files.sma.de/dl/7680/PerfratioUEN100810.pdf).

4. Dierauf, T, Growitz, A, Kurtz, S, Luis, J, Cruz, B. et al. 2013. NREL/TP-5200-57991: weather-corrected performance ratio. Technical Report.

5. Tsankov, Plamen. "Study Of The Temperature Coefficients Of Amorphous And Polycrystalline Silicon Photovoltaic Modules Under Real Operating Conditions". 2015

6. https://power.larc.nasa.gov/data-access-viewer/. POWER Data Access Viewer NASA. Accessed on May 17, 2018

7. D. L. King, "Photovoltaic Module and Array Performance Characterization Methods for All System Operating Conditions," NREL/SNL Program Review, AIP Press, 1996, pp.347-368 